\title{
Intermittent self-catheterization and the risk of squamous cell cancer of the bladder: An emerging clinical entity?
}

\author{
Rowan G. Casey, MD, FRCSUrol; Ivor M. Cullen, MD, MRCSl; Tom Crotty, FRCSPath;" David M. Quinlan, MD, \\ FRCSUrol
}

\begin{abstract}
There are only 7 cases reported in the literature of squamous cell cancer of the bladder in patients performing intermittent selfcatheterization (ISC). We report on an eighth case, and the first case described in a patient with a Mitrofanoff continent appendicovesicostomy. A description of the case and review of the literature are presented. Risk factors for squamous cell cancer include recurrent urinary tract infections, keratinising squamous metaplasia (leukoplakia) and local mucosal trauma from intermittent selfcatheterization. There is no recognized or validated monitoring program for patients performing ISC who may also have these risk factors. Reasonable protocols may include regular urinary cytology and cystoscopy with random or targeted bladder biopsies. Squamous cell cancer may present late in this cohort of patients and is associated with a dismal prognosis.
\end{abstract}

Can Urol Assoc J 2009;3(5):E51-E54

\section{Introduction}

Squamous cell cancer (SCC) of the bladder usually occurs secondary to bilharzia in the Middle East, Southeast Asia and South America, where schistosomiasis is endemic and accounts for $59 \%$ to $75 \%$ of cases. However, in western regions, SCC of the bladder usually constitutes only $1.2 \%$ to $4.5 \%$ of all bladder cancers, and these cases are usually secondary to prolonged indwelling catheters, especially in spinal cord-injured patients. This association with SCC has been documented for the last 30 years, ${ }^{1}$ and a $10 \%$ incidence of bladder SCC in patients with an indwelling catheter for $\geq 10$ years has been recognized. ${ }^{2}$ SCC of the bladder may also occur secondary to other chronic irritants, such as bacterial infections, foreign bodies (catheters, bladder calculi) and chronic bladder outlet obstruction. More rarely, there are reports of SCC of the bladder following intravesical Bacillus Calmette-Guéri (BCG), ${ }^{3}$ systemic cyclophosphamide therapy, ${ }^{4}$ and suprapubic catheters. ${ }^{5}$

Lapides and colleagues introduced the concept of clean intermittent self-catheterization (ISC) in 1972 as a means of avoiding long-term catheterization or surgery. ${ }^{6}$ It was associated with low intravesical pressures, urinary bacterial wall translocation and thus infection, in a variety of neurogenic and non-neurogenic bladder disorders. This technique has been successful in a large number of adults and children on follow-up of more than 20 years. ${ }^{7,8}$ Indeed, it is reported that clean ISC is more suitable than indwelling catheterization in patients who require long-term bladder drainage as a means of minimizing the histological changes that occur in the bladder mucosa that may predispose and lead to malignant transformation. 9,10

There are 7 reported cases in the published literature of SCC of the bladder due to a variety of reasons in patients using clean ISC (Table 1). ${ }^{11-14}$ There may be a synergistic association of leukoplakia, persistent bacteriuria, direct catheter trauma and keratinizing squamous metaplasia with progression to SCC in these cases. Squamous metaplasia, which initially may be adaptive and protective, may also be responsible for progression towards malignant transformation; keratinisation (leukoplakia) is well-recognized as a premalignant histological entity. ${ }^{9,15}$

\section{Case presentation and management}

A 45-year-old woman with a 24-year history of neurogenic bladder due to progressive multiple sclerosis underwent a Mitrofanoff appendicovesicostomy and began ISC via the continent stoma. She subsequently developed intermittent and infrequent urinary tract infections (UTIs) that later resolved with antibiotic treatment. Annual urology review consisted of renal ultrasound and clinical examination. Twelve years later, she presented with difficulty self-catheterizing via the Mitrofanoff stoma. She had no dysuria, frequency, hematuria, or rigours but had a history of weight loss of $14 \mathrm{lbs}(6.3 \mathrm{~kg})$ over the preceding 2 months. Clinical examination was unremarkable.

Flexible cystoscopy through the Mitrofanoff appendicovesicostomy revealed a raised flap visualised in the lumen of the appendiceal stoma. The Mitrofanoff stoma was catheterised to "bed down" the flap for 2 weeks. On readmission, the Mitrofanoff lumen was completely obstructed and self-catheterization was not possible. Rigid cystoscopy through the urethra 
Casey et al.

Table 1. Clinical features of 8 reported SCC cases in ISC patients

\begin{tabular}{|c|c|c|c|c|c|c|c|}
\hline Source & Age & Sex & Indication for ISC & $\begin{array}{l}\text { Duration of } \\
\text { ISC, yrs }\end{array}$ & Recurrent UTI & Presenting symptoms & $\begin{array}{l}\text { Keratinising squa- } \\
\text { mous metaplasia }\end{array}$ \\
\hline Kaye et al. & 80 & Female & Neurogenic bladder & 14 & $\begin{array}{l}\text { Asymptomatic } \\
\text { bacteriuria }\end{array}$ & Frank hematuria & Yes \\
\hline Sene et al. & 69 & Female & Underactive bladder & 4 & Yes & Frank hematuria & $\begin{array}{c}\text { Squamous } \\
\text { metaplasia/dysplasia } \\
+\mathrm{CIS}\end{array}$ \\
\hline Zaidi et al. & 37 & Female & $\begin{array}{c}\text { Spina bifida - } \\
\text { underactive, VUR }\end{array}$ & 19 & Yes & Frank hematuria & Yes \\
\hline Pattison et al. & 38 & Female & $\begin{array}{c}\text { Traumatic } \\
\text { paraplegia/incomplete } \\
\text { emptying }\end{array}$ & 8 & Yes & Micro hematuria & N/A \\
\hline Pattison et al. & 52 & Male & $\begin{array}{l}\text { Urethral dilatation for } \\
\text { Orandi urethroplasty }\end{array}$ & 23 & Yes & Bladder stones & Yes \\
\hline Pattison et al. & 34 & Female & $\begin{array}{l}\text { Incomplete emptying } \\
\text { (non neuropathic) }\end{array}$ & 6 & Yes & Constant suprapubic pain & N/A \\
\hline Pattison et al. & 19 & Male & Cloacal abnormality & 15 & Yes & $\begin{array}{l}\text { Bladder stones, } \\
\text { suprapubic pain }\end{array}$ & N/A \\
\hline Casey et al. & 45 & Female & $\begin{array}{l}\text { Incomplete } \\
\text { emptying/MS }\end{array}$ & 12 & Yes & $\begin{array}{c}\text { Mitrofanoff } \\
\text { blocked/recurrent UTI }\end{array}$ & Yes \\
\hline
\end{tabular}

revealed an exophytic mass on the left lateral wall of the bladder, which was covered in keratinous debris. As a result, a transurethral resection of this mass was undertaken. Histologically, it was identified as well-differentiated keratinising squamous cell carcinoma, with invasion of the muscularis propria in a number of fragments. She underwent a radical cystectomy en bloc with Mitrofanoff stomal resection, bilateral pelvic node clearance and ileal conduit formation. The bladder was observed to be fixed to the right side of the pubic bone and both obturator fossae. No obvious gross nodes were involved. Histologically, this tumour was found to be moderately to well-differentiated invasive bladder squamous cell cancer T4NOMO.

Three months following discharge, the patient was readmitted to hospital with a presumed UTI accompanied by raised serum white cell count and rigors. Mid-stream urinalysis was negative for UTI. A computed tomography scan of her abdomen and pelvis revealed tumour recurrence on the right side of the pelvis. She underwent palliative radiotherapy and died 8 months later from recurrent disease.

\section{Discussion}

To our knowledge, this is the first documented case in the literature of SCC of the bladder following appendicovesicostomy, and the eighth case in a patient performing ISC. The presentation in this case was atypical of episodes of failure to catheterize. In most reported cases, performing ISC may have masked symptoms, such as hematuria and recurrent UTI. As in this and other cases, the bladder epithelium distant from the tumour remained transitional in nature, suggesting that direct trauma by the catheter may play a significant role, and thus adding further strength to the theory of "local trauma" as a causative factor in the pathogenesis of SCC in patients that self-catheterize. ${ }^{11,13}$ Recurrent UTI has been previously documented as playing a role in SCC carcinogenesis. Lapides and colleagues' original concept was to reduce the risk of recurrent UTI by reducing bladder mucosal pressure and ischemia with selfcatheterization. ${ }^{6}$ While serious infection rates may be reduced by self-catheterization, there remains a group of patients that continue to develop significant symptomatic or asymptomatic bacteriuria. 


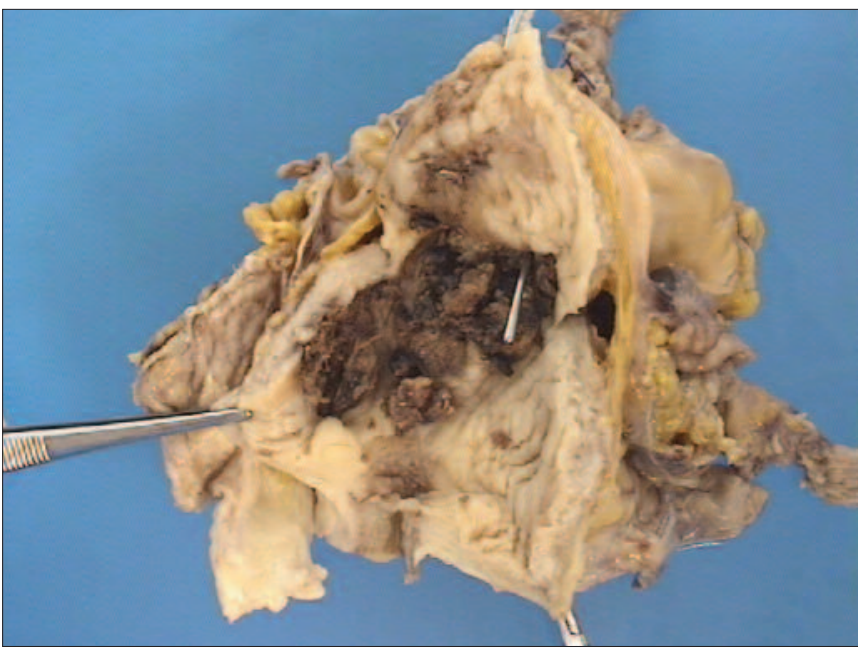

Fig. 1. Opened surgical bladder specimen demonstrating squamous cell cancer centrally (dark brown) with tip of probe entering bladder through Mitrofanoff in centre of squamous cell carcinoma.

Keratinising squamous metaplasia, present in a number of these cases, is a significant risk factor for the development of SCC, and increases with the extent of bladder involvement in patients performing ISC. ${ }^{15,16}$ There may be significant lag time between development of keratinising squamous metaplasia and development of a bladder tumour (4 to 28 years)..$^{15}$ However, the reported incidence of SCC synchronous with keratinising squamous metaplasia at time of diagnosis ranges from $9 \%$ to $22 \% .{ }^{15,17}$ Keratinising squamous metaplasia has also been reported in association with other conditions that may be additive, such as bladder calculi, urinary outflow obstruction and neurogenic bladder dysfunction (Fig. 1, Fig. 2). ${ }^{15,18}$ The cost/benefit analysis of monitoring patients performing ISC remains debatable, with cytological and cystoscopic screening resulting in significant costs in this patient population.

In paraplegic patients with long-term indwelling catheters, Broecker and colleagues suggest annual cystoscopy and urine cytology with random bladder biopsies every 1 to 2 years. ${ }^{19}$ Locke and colleagues suggest screening with annual urine cytology and, when positive, a complete urological evaluation. Outcomes are poor with cytology alone, particularly in the presence of UTI or catheter trauma. ${ }^{2}$ Navon and colleagues recommend annual cystoscopy starting 10 years following spinal cord injury and in patients with recurrent or chronic UTI. ${ }^{20}$ However, these studies have never been validated and challenged by other authors. ${ }^{21}$

A number of urinary markers are currently under investigation for early detection of SCC, including S100A7, 22 SCC antigen, BCL2, p53 drug, ${ }^{23}$ nitric oxide, ${ }^{24}$ cyclooxygenase- $2^{25}$ and cytokeratin. ${ }^{26}$ These markers may well represent an effective and practical approach to screening high-risk patients.

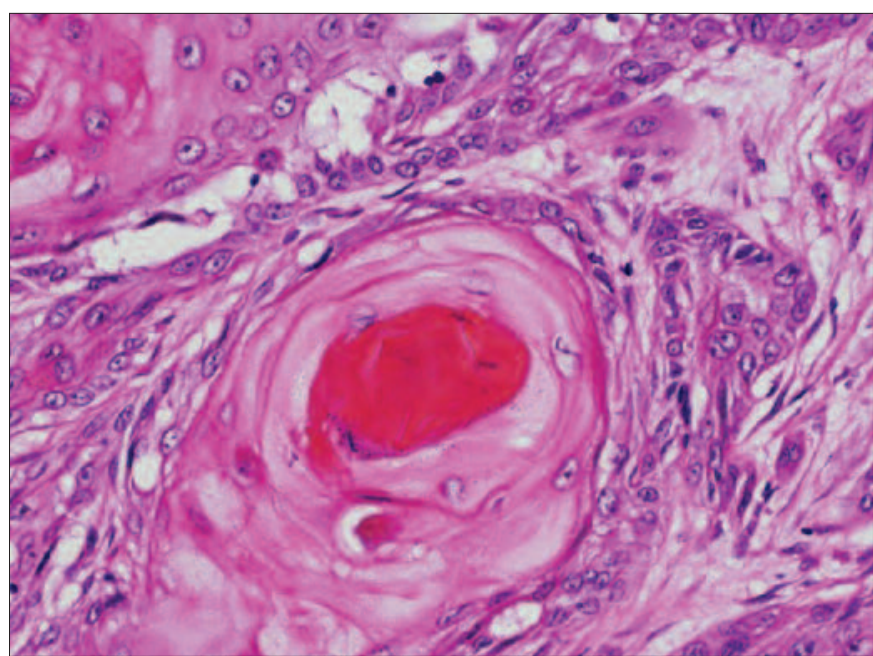

Fig. 2. Classic keratin pearl of keratinising squamous metaplasia (H\&E staining).

In addition to reducing the risk of UTI, bladder calculi and other irritants, we are considering introducing an effective monitoring program for all patients on a self-catheterizing regimen to assist with early detection and prevention of this malignancy, and improve the current dismal reported results associated with SCC of the bladder.

From the Department of Urology and “Pathology, St. Vincent's University Hospital, Elm Park, Dublin 4, Ireland

This paper has been peer-reviewed.

Competing interests: None dedared.

\section{References}

1. Kaufman JM, Fam B, Jacobs SC, et al. Bladder cancer and squamous metapalsia in spinal cord injury patients. J Urol 1977;118:967.

2. Locke JR, Hill DE, Walzer Y. Incidence of squamous cell carcinoma in patients with long term catheter drainage. J Urol 1985;133:1034-5.

3. Brenner DW, Yore LM, Schellhammer PF. Squamous cell carcinoma of bladder after successful intravesical therapy with bacillus Calmette-Guerin. Urology 1989;34:93-5.

4. Stein JP, Skinner EC, Boyd SD, et al. Squamous cell carcinoma of the bladder associated with cyclophosphamide therapy for Wegeners granulomatosis: a report of 2 cases. J Urol 1993; 149:588-9.

5. Schaafsma RJH, Delaere KPJ, Theunissen PHMH. Squamous cell carcinoma of suprapubic cystostomy tract without bladder involvement. Spinal Cord 1999;37:373-4.

6. Lapides J, Diokno AC, Silber SJ, et al. Clean, intermittent self-catheterisation in the treatment of urinary tract disease. J Urol 1972;107:458-61.

7. Lindehall B, Abrahamsson $K$, Jodal $U$, et al. Complications of clean intermittent catheterisation in young female patients with myelomeningocele: 10 to 19 years follow up. J Urol 2007;178:1053-5.

8. Diokno AC, Sonda LP, Hollander JB, et al. Fate of patients started on clean intermittent self-catheterization therapy 10 years ago. J Urol 1983;129:1120-2.

9. Delnay KM, Stonehill WH, Goldman H, et al. Bladder histological changes associated with chronic indwelling urinary catheter. J Urol 1999;161:1106-8.

10. Vaidyanathan $S$, Mansour P, Soni BM, et al. The method of bladder drainage in spinal cord injury patients may influence the histological changes in the mucosa of neuropathic bladder— a hypothesis. BMC Urol 2002;2:1-7. 
Casey et al.

11. Kaye MC, Levin HS, Montague DK, et al. Squamous cell carcinoma of the bladder in a patient on intermittent self-catheterisation. Cleve Clin J Med 1992;59:645-6.

12. Pattison S, Choong S, Corbishley SM, et al. Squamous cell carcinoma of the bladder, intermittent selfcatheterization and urinary tract infection - is there an association? BJU Int 2001;88:441.

13. Sene AP, Massey JA, McMahon RTF, et al. Squamous cell carcinoma in a patient on clean intermittent self catheterization. Br J Urol 1990;65:213-4.

14. Zaidi SZ, Theaker JM, Smart CJ. Squamous cell carcinoma in a patient on clean intermittent self catheterization (case report). Br J Urol 1997;80:352-3.

15. Khan MS, Thornhill JA, Gaffney E, et al. Keratinising squamous metaplasia of the bladder: natural history and rationalization of management based on review of 54 years experience. Eur Urol 2002;42:469-74.

16. Serretta V, Pomara G, Piazzo F, et al. Pure squamous cell carcinoma of the bladder in Western Countries. Eur Urol 2000;37:85-9.

17. O'Flynn JD, Mullaney J. Leukoplakia of the bladder. A report on 20 cases, including 2 cases progressing to squamous cell carcinoma. Br J Urol 1967;39:461-71.

18. Morgan RJ, Cameron KM. Vesical leukoplakia. Br J Urol 1980;52:96.

19. Broecker BH, Klein FA, Hackler RH. Cancer of the bladder in spinal cord injury patients. J Urol 1981;125: 196-7.
20. Navon JD, Soliman H, Khonsari F, et al. Screening cystoscopy and survival of spinal cord injured patients with squamous cell cancer of the bladder. J Urol 1997;157: 2109-11.

21. Hamid R, Bycroft J, Arya M, et al. Screening cystoscopy and biopsy in patients with neuropathic bladder and chronic suprapubic indwelling catheters: is it valid? J Urol 2003;170:425-7.

22. Ostergaard M, Wolf H, Orntoft TF, et al. Psoriasin (S100A7): a putative urinary marker for the follow up of patients with bladder squamous cell carcinomas. Electorphoresis 1999;20:349-54.

23. Tsukamoto T, Kumamoto Y, Ohmura K, et al. Squamous cell carcinoma-associated antigen in uroepithelial carcinoma. Urology 1992;40:477-83.

24. Bartoletti R, Cai T, Nesi G, et al. Qualitative and quantitive anaylsis of angiogenetic factors in transitional cell bladder carcinoma: relationship with clinical course at 10 years follow-up. Oncol Rep 2005; 14:251-5.

25. Shirahama T, Sakakura C. Overexpression of cyclooxygenase-2 in squamous cell carcinoma of the urinary bladder. Clin Cancer Res 2001;7:558-61.

26. Attallah AM, Sakr HA, Ismail H, et al. Rapid diagnosis and follow up of bladder cancer patients using urinary high molecular weight cytokeratins. World I Urol 2006;24:345-52.

Correspondence: Mr. Rowan Casey, Urology Specialist Registrar, Dept. of Urology, St. James's Hospital, Dublin 2, Ireland; fax 00353 (01) 4284090; rowcasey@rcsi.ie 